\title{
Cosmic ray neutrons provide an innovative technique for estimating intermediate scale soil moisture
}

AUTHORS:

Thigesh Vather ${ }^{1,2}$ (ID

Colin Everson ${ }^{1,2}$ (D)

Michael Mengistu ${ }^{3}$ iD

Trenton Franz ${ }^{4}$

\section{AFFILIATIONS:}

${ }^{1}$ The Centre for Water Resources Research, University of KwaZulu-Natal, Pietermaritzburg, South Africa

${ }^{2}$ South African Earth Observation Network, Pietermaritzburg, South Africa

${ }^{3}$ South African Weather Service, Pretoria, South Africa

${ }^{4}$ School of Natural Resources, University of Nebraska-Lincoln, Lincoln, Nebraska, USA

\section{CORRESPONDENCE TO:}

Thigesh Vather

\section{EMAIL:}

thigesh@saeon.ac.za

\section{DATES:}

Received: 12 Dec. 2017

Revised: 29 Mar. 2018

Accepted: 22 Apr. 2018

Published: 30 July 2018

\section{KEYWORDS:}

cosmic ray probe; area-average; in-situ soil measurements; hydrology

\section{HOW TO CITE:}

Vather T, Everson C, Mengistu

M, Franz T. Cosmic ray neutrons provide an innovative technique for estimating intermediate scale soil moisture. S Afr J Sci. 2018;114(7/8), Art. \#2017-0422, 9 pages. http://dx.doi.org/10.17159/ sajs.2018/20170422

\section{ARTICLE INCLUDES: \\ $\times$ Supplementary material \\ $\times$ Data set}

\section{FUNDING:}

Partnerships for Enhanced Engagement in Research (USA); South African Agency for Science and Technology Advancement; United States Agency for International Development; University of KwaZulu-Natal; University of Pretoria

(C) 2018. The Author(s). Published under a Creative Commons Attribution Licence.
Soil moisture is an important hydrological parameter, which is essential for a variety of applications, thereby extending to numerous disciplines. Currently, there are three methods of estimating soil moisture: ground-based (in-situ) measurements; remote sensing based methods and land surface models. In recent years, the cosmic ray probe (CRP), which is an in-situ technique, has been implemented in several countries across the globe. The CRP provides area-averaged soil moisture at an intermediate scale and thus bridges the gap between in-situ point measurements and global satellite-based soil moisture estimates. The aim of this study was to test the suitability of the CRP to provide spatial estimates of soil moisture. The CRP was set up and calibrated in Cathedral Peak Catchment VI. An in-situ soil moisture network consisting of time-domain reflectometry and Echo probes was created in Catchment $\mathrm{VI}$, and was used to validate the CRP soil moisture estimates. Once calibrated, the CRP was found to provide spatial estimates of soil moisture, which correlated well with the in-situ soil moisture network data set and yielded an $R^{2}$ value of 0.845 . The use of the CRP for soil moisture monitoring provided reliable, accurate and continuous soil moisture estimates over the catchment area. The wealth of current and potential applications makes the CRP very appealing for scientists and engineers in various fields.

\section{Significance:}

- The cosmic ray probe provides spatial estimates of surface soil moisture at an intermediate scale of 18 hectares.

- A single cosmic ray probe can replace a network of conventional in-situ instruments to provide reliable soil moisture estimates.

- The cosmic ray probe is capable of estimating soil moisture in previously problematic areas (saline soil, wetlands, rocky soil).

- Cosmic ray probes can provide data for hydro-meteorologists interested in land-atmosphere interactions.

- The cosmic ray probe estimates can be promising for remote sensing scientists for product calibration and validation.

\section{Introduction}

There has been a continual need to monitor and measure the various parameters in land surface hydrology, in order to deepen the understanding of hydrological processes, their importance in the hydrological cycle and their interactions between each other. ${ }^{1,2}$ Soil moisture is an important parameter in the hydrological cycle and impacts a variety of applications, including agricultural management, climate and weather applications, flood and drought forecasting and groundwater recharge.

Soil moisture is a difficult parameter to continuously monitor and measure at a catchment scale because of its heterogeneous characteristics. It varies both spatially and temporally and is thus a dynamic resource. Currently there are three methods of estimating soil moisture: (1) ground-based (in-situ) measurements, which are carried out using field instruments; (2) remote sensing based methods, which use specialised sensors on satellites and aircrafts and (3) land surface models, which use meteorological data as inputs, at a predefined spatial resolution..$^{3,4}$ Inherently, each of these methods possess their respective advantages and limitations, constraining their effectiveness for hydrological applications. ${ }^{5}$

In-situ measurements of soil moisture are the conventional methods used by several disciplines. The point measurements obtained cannot adequately represent the spatial characteristics of soil moisture and thus limit our understanding of feedbacks to the atmosphere. However, these point measurements play a key role in a variety of large-scale applications and are invaluable as both calibration and validation data. ${ }^{6}$ Recently, the cosmic ray probe (CRP) method, which is an innovative in-situ instrument, has been developed and implemented in numerous countries across the globe. ${ }^{7}$ Countries such as the USA, Australia, Germany and the United Kingdom have invested greatly in this technology and have created national soil moisture monitoring networks. The CRP technique obtains the area-averaged soil moisture, at an intermediate scale, by observing and measuring the cosmic ray neutrons above the soil surface. ${ }^{8,9}$ The CRP has not been evaluated in South Africa, thus the aim of this study was to test and evaluate the suitability of the CRP to provide spatial estimates of soil moisture, using the Cathedral Peak Catchment $\mathrm{VI}$ as a study area. The Cathedral Peak area is important as it is the 'water towers' of the region, as much of our water is generated in this area. The CRP was set up in Catchment VI, as it is already heavily instrumented, and an added soil moisture instrument would add value to any potential research done in the area.

The potential applications of the CRP make it appealing to scientists in various fields, such as agricultural and ecological monitoring, climate science, drought and flood forecasting, as well as slope stability. ${ }^{10}$ It should also be noted that the discipline of remote sensing can benefit greatly from this innovative technology by using CRP estimates for both the calibration and validation of sensors and data products, as it overcomes the spatial 
limitations of conventional in-situ soil moisture estimates. ${ }^{10}$ The use of the CRP across different continents results in measurement technique consistency, which reduces the uncertainties related to in-situ measurements that use a variety of probe types or methods. ${ }^{11}$

\section{In-situ methods of soil moisture measurement}

\section{Conventional methods of soil moisture estimation}

In-situ soil moisture measurements have played a key role for a variety of large-scale applications and have been invaluable as calibration and validation data for satellite-based products, sensors and models. ${ }^{6}$ These include the gravimetric, neutron scattering and time-domain reflectance (TDR) methods. ${ }^{12}$ The major limitation of all conventional in-situ methods is that they provide point measurements, which do not account for the spatial characteristics of soil moisture. ${ }^{13}$ No single point measurement can be entirely representative of larger areas, because of the heterogeneity that exists in soil properties, topography, land cover and meteorological conditions. ${ }^{6}$ To overcome this limitation, dense soil moisture networks can be set up. However, the high costs of operation and maintenance make the set-up of the network financially unfeasible, ${ }^{6}$ particularly for the objective of establishing a national scale network.

\section{Cosmic ray probe}

The CRP is the only in-situ technique that can obtain the average soil moisture content over hundreds of square metres - something that would require a dense in-situ point measurement network. ${ }^{9,14}$ The CRP estimates soil moisture hourly at a shallow measurement depth that ranges between $0.12 \mathrm{~m}$ and $0.72 \mathrm{~m}$. The CRP system consists of neutron counters (moderated and bare tubes); a data logger which measures barometric pressure, humidity and temperature; a telemetry system with antenna to connect to an iridium satellite; and a battery and solar panel for powering the system.

\section{Production of cosmic ray neutrons}

Cosmic ray neutrons originate in space, where they are produced by the blast waves of exploding stars. Some of these high energy particle flows in space reach the earth's atmosphere, where they are affected by the earth's magnetic field. ${ }^{15}$ The high energy particles are captured into the earth's atmosphere and collide with atmospheric nuclei to initiate a cascade of secondary cosmic rays..$^{14}$ Fast neutrons are created, as these secondary cosmic rays pass through the atmosphere and then through the top few metres of the biosphere, hydrosphere and lithosphere. ${ }^{10}$ These fast neutrons undergo elastic collisions with nuclei present in the soil, thereby losing energy. ${ }^{10}$ Some of the fast neutrons are adsorbed by the soil during the collision, whilst others will be scattered above the surface of the soil. ${ }^{15}$ The cosmic ray neutrons lose energy with each collision, therefore high energy neutrons become fast neutrons (in the atmosphere), which further lose energy and become thermal neutrons (in the soil). As a result of fast neutrons being strongly moderated by hydrogen present in the environment, their measured intensities relate to changes in soil moisture, as well as other hydrogen sources at the earth's surface. ${ }^{8,9,16}$

\section{Moderation of neutrons}

According to Ochsner et al. ${ }^{14}$ and Jiao et al. ${ }^{15}$, the moderation process of cosmic ray neutrons depends on three factors:

1. The scattering probability or the elemental scattering cross-section.

2. The logarithmic decrement of energy per collision.

3. The number of atoms of an element per unit mass of material, which is proportional to the concentration of the element and to the inverse of its mass number.

The combination of the abovementioned factors defines the neutron stopping power of a material. ${ }^{14}$ Hydrogen, which is found mainly as water in the soil, plays the most significant role in moderating cosmic ray neutrons in the soil. Hydrogen has by far the highest stopping power of any element ( $\sim 25$ times greater), as the hydrogen atom has a high probability of scattering a neutron as a result of its fairly large elastic scattering cross-section. ${ }^{15}$ Hydrogen is the most efficient element with regard to the decrement of energy per collision and has a low atomic mass and makes up a substantial portion of all the atoms in many soils, as a consequence of the presence of water in the soil. ${ }^{15}$ The presence of water within the soil pores plays an important and central role in moderating the concentration of cosmic ray neutrons above the soil surface. ${ }^{17}$

\section{Cosmic ray probe measurements}

The fast neutrons that are produced in the air and soil travel in all directions between the air and soil, thus creating an equilibrium concentration of neutrons. This equilibrium concentration is shifted because of changes (addition or subtraction) in the hydrogen content of the media. The soil moisture content is estimated by the concentration of cosmic ray neutrons, which are generated within the soil and moderated predominantly by hydrogen, before being diffused back into the atmosphere..$^{16}$ The soil moisture content can therefore be inferred directly from these neutron fluxes. ${ }^{10}$

The CRP system consists of two sensors, which are the moderated and bare sensor. The moderated sensor is shielded by a 25.4-mm-thick polyethylene and measures the fast neutron intensity above the soil surface. The fast neutron intensity above the soil surface is inversely proportional to the soil moisture content. ${ }^{7}$ The bare tube (unshielded) measures the thermal neutrons, which are attributed to the water above the soil surface (biomass and snow).

Measurement footprint and depth of the cosmic ray probe estimates

The CRP senses all hydrogen present within the distance that fast neutrons can travel in air, water, soil and other materials near the earth's surface. Thus, the measurement distance varies according to the density and chemical composition of the material. ${ }^{14}$ The footprint (measurement area) of the CRP is defined as the area around the probe from which $86 \%$ of the counted neutrons arise, is primarily associated with the chemical and physical properties of the air and is inversely proportional to the air density. ${ }^{15}$

The radial footprint of the CRP is reliant on the neutrons' ability to travel hundreds of metres from their source, through the neutrons scattering in the air. ${ }^{7}$ Hence the scattering properties of air significantly affect the diameter of the footprint. ${ }^{15}$ When the CRP is placed in a static position a few metres above the ground, it has a radial footprint of $\sim 240 \mathrm{~m}$ ( $\sim 480$ m diameter) at sea level. ${ }^{7}$

The effective measurement depth is the thickness at which $86 \%$ of counted neutrons arise, which depends strongly on the soil moisture content. ${ }^{14}$ The measurement depth ranges from $0.12 \mathrm{~m}$ to $0.7 \mathrm{~m}$ and is inversely proportional to the soil moisture content. ${ }^{9}$ The decrease in the measurement depth as a result of an increase in soil moisture is nonlinear.

The cosmic ray technology consists of instruments that can be used either in a fixed position (CRP) or in a moving vehicle (cosmic ray rover). The CRP is used to obtain continuous measurements of an area which are normally summed to give hourly neutron counts, whilst the roving method can be used for mapping soil moisture over large areas. ${ }^{18}$

The CRP method has several advantages: the method is passive and non-contact (non-invasive); the system is easily automated and portable; and it has minimal power requirements. Applications are not limited to soil moisture, as the CRP can also be used to estimate above-ground biomass and snow depth. Most importantly, the measurement footprint is at an intermediate scale of around $18 \mathrm{ha}$. The method requires low data processing and is insensitive to soil texture, bulk density or surface roughness. ${ }^{8-10,15-17,19,20}$

The CRP does, however, require calibration, which is performed by obtaining corresponding measurements of area-averaged soil moisture and neutron intensity. The area-averaged soil moisture is obtained from ground-based point measurements, by collecting several soil samples within the CRP measurement area and determining the average soil moisture per calibration. The measured neutron intensities need to 
be adjusted and corrected for variations in location, incoming highenergy particles, atmospheric pressure, absolute humidity and changes in biomass. ${ }^{21}$

It is recommended that a minimum of two field calibrations are conducted, to obtain reliable estimates of soil moisture. These two calibrations should be carried out in opposing seasons, to calibrate the instrument over contrasting soil moisture statuses (a dry calibration in winter and a wet calibration in summer). ${ }^{18}$ Representative soil samples of the measurement area are required to be analysed, to correct the calibration function for lattice water (water of crystallisation not measured with conventional techniques) and water in organic matter. ${ }^{14}$

For absolute volumetric water content (VWC), studies have shown that a minimum of three calibrations should be conducted to obtain soil moisture estimates with an error less than 2-3\%VWC. The CRP can provide useful data even if the calibration is not conducted. For use in flood forecasting or land surface model data assimilation, the relative changes (patterns) can be used from the corrected neutron counts directly.

\section{Methodology}

\section{Study site}

The Cathedral Peak Research Catchment VI lies within the KwaZulu-Natal Province of South Africa, in the Tugela Catchment, as shown in Figure 1. It comprises 15 gauged catchments that are situated on the little Berg, located below the Drakensberg escarpment, which creates a natural border between the northeastern side of Lesotho and South Africa. ${ }^{22}$
The Drakensberg mountain range is the highest mountain range in South Africa and gives rise to many of the rivers which are of great economic importance to the country. ${ }^{23}$ Catchment VI has a catchment area of $0.68 \mathrm{~km}^{2}$ and is located by latitude $28.99^{\circ} \mathrm{S}$ and longitude $29.25^{\circ} \mathrm{E}$. It is moderately dissected by streams and has a stream density of $3.25 \mathrm{~km} / \mathrm{km}^{2}{ }^{23}$ The altitude ranges from $1860 \mathrm{~m}$ at the weir (northernmost point of the catchment) to $2070 \mathrm{~m}$ at the highest point of the catchment, with an average catchment slope of $19 \% .{ }^{24}$

The land cover of Catchment $\mathrm{VI}$ is uKhahlamba basalt grassland. ${ }^{25}$ The soils in the catchments are moderately weathered immature soils, which are primarily derived from basalt. ${ }^{26}$ The soils in the catchment are classified as lateritic yellow and red earths, with heavy black soils occurring in saturated zones and along stream banks. ${ }^{27}$ There is a contrast in soil properties among the soil layers. The topsoil has a friable consistency, which results in rapid infiltration, whilst the subsoil has a very high clay content, which results in poor infiltration. The topsoil has a high organic matter content (6-10\%), which results in a high waterholding capacity. ${ }^{24}$ The region is characterised climatically by its cold dry winters and hot wet summers. The mean annual precipitation is $1400 \mathrm{~mm}$, with $85 \%$ falling between October and March. ${ }^{22}$ Catchment VI has a mean annual precipitation of $1299 \mathrm{~mm} .{ }^{27}$

\section{Cosmic ray probe}

The CRP was installed on 28 February 2014 in the Cathedral Peak Catchment VI (Figure 2).

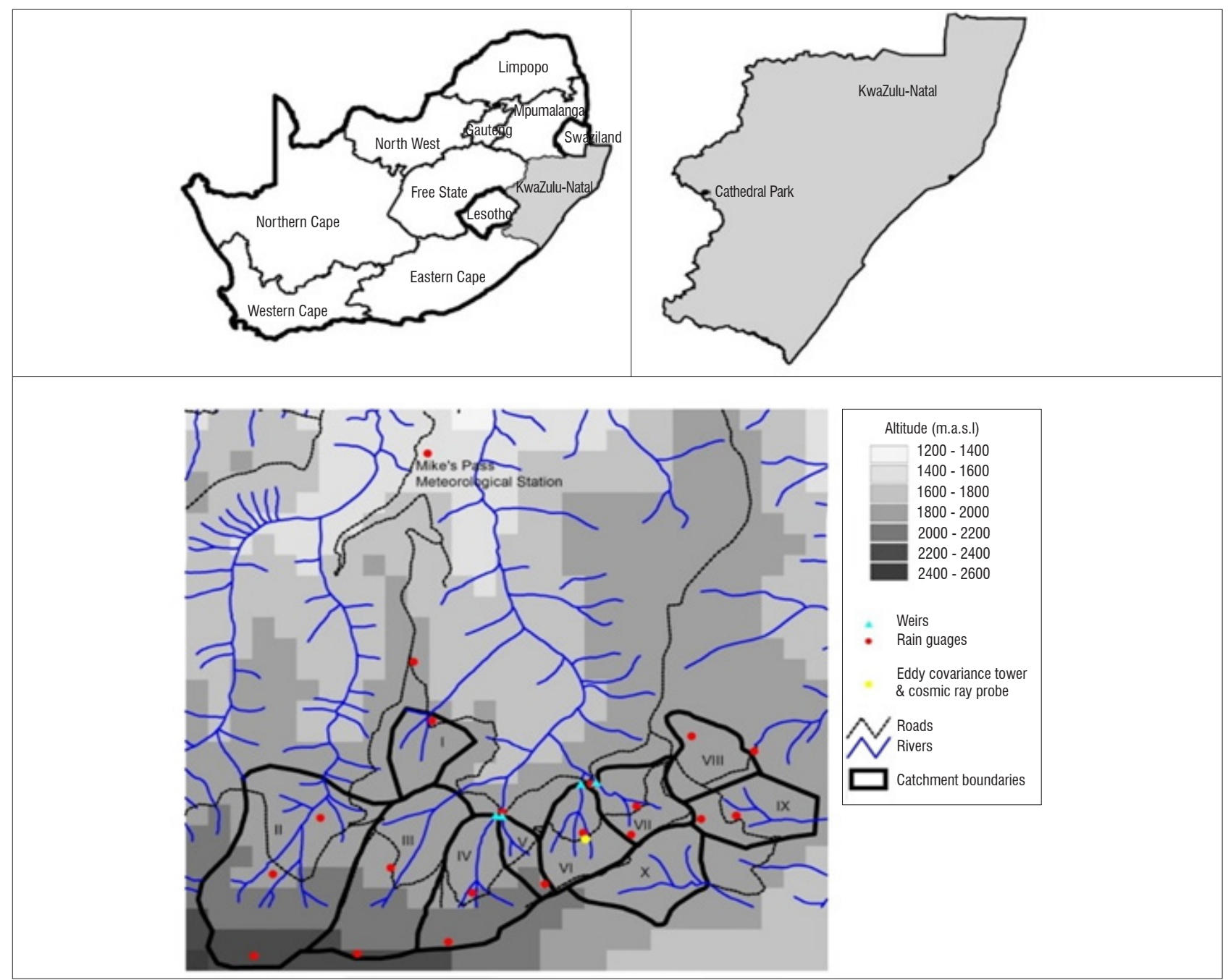

Figure 1: Location of Cathedral Peak Catchment VI, within the Tugela Catchment, in the KwaZulu-Natal Province, South Africa. 


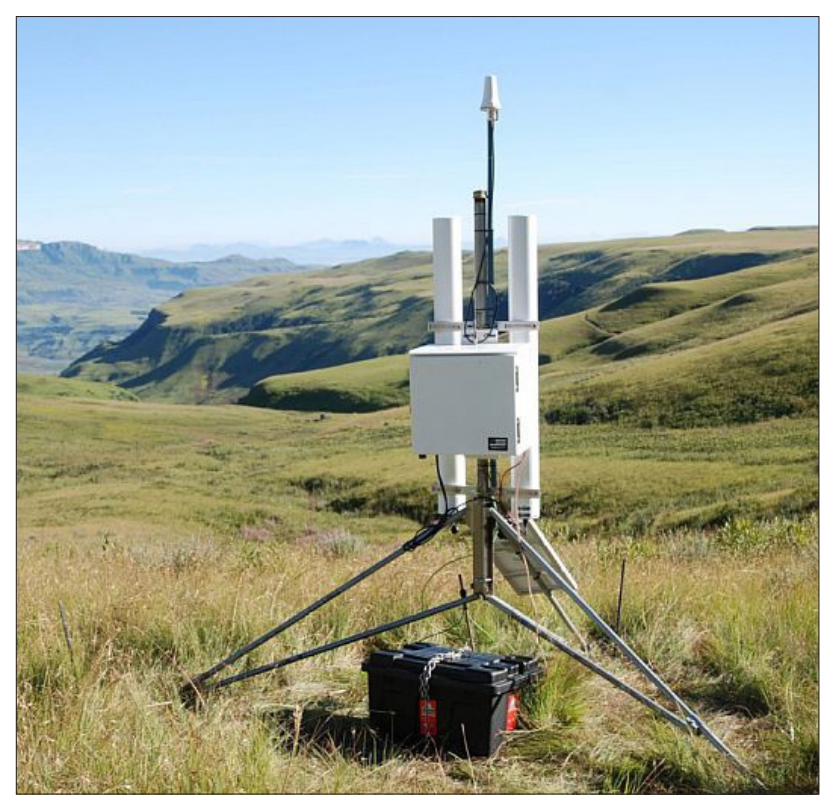

Photo: Thigesh Vather

Figure 2: The cosmic ray probe in Cathedral Peak Catchment VI.

The calibration procedure involves obtaining an estimate of the areaaveraged soil moisture content over the CRP measurement footprint by gravimetric sampling and the subsequent neutron intensity. Soil samples were taken at three radial rings, extending outwards from the CRP. The radial rings were situated at distances of $25 \mathrm{~m}, 100 \mathrm{~m}$ and $200 \mathrm{~m}$ from the CRP (Figure 3). At each of the three rings, eight points were taken at an equal distance along the circumference of the ring. At each sample point, soil samples were taken at different depths.

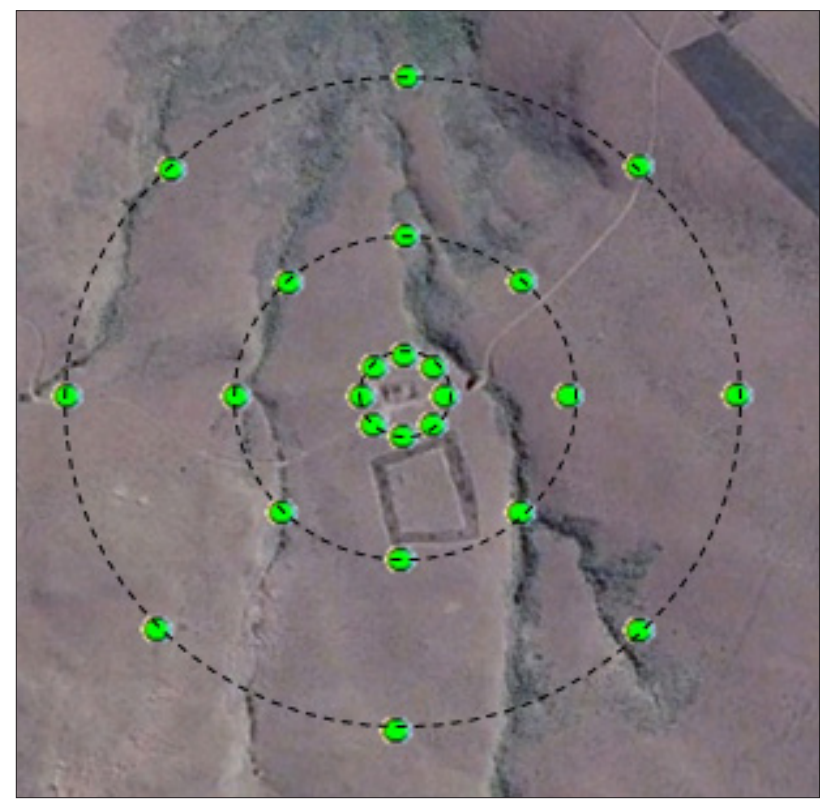

Figure 3: Calibration sampling points along three radial rings extending outwards from the cosmic ray probe (at $25 \mathrm{~m}, 100 \mathrm{~m}$ and $200 \mathrm{~m})$. At each sample point, soil samples were taken at different depths.

Four calibrations were carried out over a period of 8 months. The calibration dates were 9 July 2014 (winter), 28 August 2014 (spring), 2 December 2014 (summer) and 22 January 2015 (late summer).

The gravimetric method was used to obtain soil samples within the CRP footprint, to determine the area-average soil moisture for the calibration of the CRP. The gravimetric soil moisture content is expressed, by weight, as the ratio of the mass of water present to the dry weight of the soil sample $(\mathrm{g} / \mathrm{g})$. The CRP, however, measures the volumetric soil moisture content, which is expressed as the ratio of volume of water to the total volume of the soil sample $\left(\mathrm{cm}^{3} / \mathrm{cm}^{3}\right)$. The calibration of the CRP requires a representative bulk density value to convert the gravimetric soil moisture content to volumetric water content. The bulk density determination was carried out by obtaining undisturbed soil cores at various locations and depths within the catchment. The average measured bulk density was $0.593 \mathrm{~g} / \mathrm{cm}^{3}$. This low bulk density value can be attributed to the soil cover, organic matter content, soil structure, porosity and the lack of compaction, as the catchment is situated in an undisturbed area.

\section{Calibration}

The final calibration was carried out once all four calibrations had been completed. The aim of the calibration was to determine the average $\mathrm{N}_{0}$ value (site-specific calibration parameter), which is the theoretical neutron intensity (counting rate) in air above dry soil (no moisture). Data from the CRP are sent hourly, via satellite link, to the COSMOS server: http://cosmos.hwr.arizona.edu/Probes/probemap.php. The calibration procedure followed that of Franz et al. ${ }^{21,28}$

The first step in the calibration procedure was to correct the neutron counts. This correction involved determining the neutron correction factors, using the following equations. ${ }^{28}$

$\mathrm{N}=\frac{\mathrm{N}^{\prime} * \mathrm{CP} * \mathrm{CWV}}{\mathrm{Cl} * \mathrm{CS}}$

Equation 1

where $\mathrm{N}$ is the corrected neutron counts per hour, $\mathrm{N}$ ' is the raw moderated neutron counts, $\mathrm{CP}$ is the pressure correction factor, CWV is the water vapour correction factor, $\mathrm{Cl}$ is the high-energy intensity correction factor, and $\mathrm{CS}$ is the scaling factor for geomagnetic latitude. ${ }^{28}$

$C P=\exp \left(\frac{P_{0}-P}{L}\right)$,

Equation 2

where $L$ is the mass attenuation length for high-energy neutrons $\left(\mathrm{g} / \mathrm{cm}^{2}\right)$, $P$ is the atmospheric pressure $(\mathrm{mb})$ at a specific site and $P_{0}$ is the reference atmospheric pressure $(\mathrm{mb}){ }^{9}$

CWV $=1+0.0054\left(P_{\text {vo }}-P_{\text {vo }}^{\text {ref }}\right)$,

Equation 3

where $P_{v 0}$ is the absolute humidity of the air $\left(\mathrm{g} / \mathrm{m}^{3}\right)$ and $P_{\mathrm{vo}}$ ref is the reference absolute humidity of the air $\left(\mathrm{g} / \mathrm{m}^{3}\right)$.

$\mathrm{Cl}=\frac{I_{m}}{I_{\text {ref }}}$

Equation 4

where $\mathrm{I}_{\mathrm{m}}$ is the selected neutron monitoring count rate at any particular point in time and $I_{\text {ref }}$ is the reference count rate for the same neutron monitor from an arbitrary fixed point in time. The neutron flux data was obtained through the neutron monitoring database (www.nmdb.eu), which provides real-time data from a global network of monitoring stations.

$C S=f(x, y, z, t)$

Equation 5

where $x, y, z$ is location and elevation, and $t$ is time.

The following calibration function was then used to determine the $\mathrm{N}_{0}$ value for each calibration ${ }^{21}$ :

$\left(\theta_{\mathrm{p}}+\theta_{\mathrm{LW}}+\theta_{\mathrm{soc}}\right)=\frac{0.0808}{\frac{\mathrm{N}}{\mathrm{N}_{0}}-0.372}-0.115$

Equation 6

Rearranging the calibration function to determine $\mathrm{N}_{0}$ :

$N_{o}=\left(\frac{N}{\frac{0.0808}{\left(\theta_{p}+\theta_{L W}+\theta_{S O C}\right)+0.115}+0.372}\right)$

Equation 7 
Rearranging the calibration function to determine VWC:

$V W C=\left(\frac{0.0808}{\left(\frac{\mathrm{N}}{\mathrm{N}_{0}}\right)-0.372}-0.115-\left(\theta_{\mathrm{LW}}+\theta_{\mathrm{Soc}}\right)\right) P_{b d}$

Equation 8

where $\theta_{p}$ is the gravimetric water content $(\mathrm{g} / \mathrm{g}), \theta_{\mathrm{LW}}$ is lattice water content $(\mathrm{g} / \mathrm{g}), \theta_{s o c}$ is soil organic carbon water content $(\mathrm{g} / \mathrm{g}), P_{b d}$ is dry soil bulk density $\left(\mathrm{g} / \mathrm{cm}^{3}\right), N$ is the corrected neutron counts per hour, and $N_{0}$ is an instrument-specific calibrated parameter. We note that soil moisture is often expressed in units of volume per cent $\left(\operatorname{VWC}(\%)=\theta p \times P_{b d} \times 100\right)$.

$\theta_{\text {soc }}$ was not determined, but was given a value of $0.01 \mathrm{~g} / \mathrm{g}$ based on published values. ${ }^{8} \theta_{\text {iw }}$ was determined to be $0.154 \mathrm{~g} / \mathrm{g}$. A $50-\mathrm{g}$ representative soil sample was sent to Activation Laboratories in Canada for $\theta_{w}$ determination by combustion at $1000^{\circ} \mathrm{C}$.

There is a need to correct for biomass. ${ }^{21}$

$\left(\theta_{p}+\theta_{L W}+\theta_{S O c}\right)=\frac{0.0808}{\frac{N}{N_{0}(B W E)}-0.372}-0.115$,

Equation 9

where BWE is the biomass water equivalent $(\mathrm{mm})$. The biomass calculation is done for vegetation types whose biomass changes with their growing stage. Because the vegetation of Catchment $\mathrm{VI}$ is short grassland, the biomass was small ${ }^{29}$ and the change in biomass in this context was therefore insignificant and a biomass correction was not required.

The neutron count $(\mathrm{N})$ for each calibration was determined as the average neutron count during which the soil samples for that calibration were obtained. These counts were used to determine the $\mathrm{N}_{0}$ value for each calibration, using the rearranged calibration Equation 7 (Table 1).

The average $\mathrm{N}$ value for the calibrations was calculated to be 3249.324 . This calculated $\mathrm{N}_{0}$ value was used in the rearranged calibration function equation (Equation 8) to determine the hourly VWC (Figure 4). The hourly CRP data (grey line) were converted into daily (black line) average to smooth the data and for comparison with other daily-derived soil moisture products. The results show that soil moisture was higher in the summer and lower in the winter (Figure 4), as expected in the summer rainfall region of South Africa.

The effective measurement depth of the CRP over the 1-year period between March 2014 and March 2015 (Figure 5), showed that the effective measurement depth ranged from $0.084 \mathrm{~m}$ to $0.148 \mathrm{~m}$, with an average effective measurement depth of $0.117 \mathrm{~m}$.

\section{Creating a soil moisture network}

It was essential to create an in-situ soil moisture network within the CRP measurement area, to obtain data that could be used to validate the calibrated CRP estimates. The in-situ soil moisture network consisted of three types of measurement instruments, which were installed on 9 July 2014: one soil pit with TDR probes inserted horizontally at depths of $0.05,0.10,0.15,0.20$ and $0.30 \mathrm{~m}$; five wireless TDR sensors $(0.12 \mathrm{~m})$ inserted vertically into the soil surface; and eight Echo probes inserted horizontally at a depth of $0.10 \mathrm{~m}$. The five wireless TDR probes and eight Echo probes were placed within the CRP's footprint area. All three sets of data were merged by weighting each point within the catchment equally, to create a representative in-situ soil moisture estimate. For consistency, only the $0.10 \mathrm{~m}$ and $0.15 \mathrm{~m}$ TDR pit data were used, which coincide with the two other in-situ measurement method depths and the effective measurement depth of the CRP. The CRP has a varying effective depth, which could be validated against the TDR pit, which has sensors at different depths; however, the aim was to test the suitability of the CRP to provide spatial estimates of soil moisture, which required a spatial validation data set and not a single point measurement.

\section{Results and discussion}

Soil moisture varies both spatially and temporally and fluxes in soil moisture content occur over short time periods and distances. The key input to the soil moisture content in Cathedral Peak Catchment VI is rainfall. Therefore, rainfall data are necessary to support and explain changes in soil moisture. Rainfall data from a rain gauge situated within Catchment VI were obtained for the 1-year period from March 2014 to March 2015 (Figure 5). The rainfall distribution showed that most of the rainfall $(73 \%)$ occurred in the summer months.

\section{Validating the $C R P$}

A time series of the CRP and in-situ soil moisture data (Figure 6) showed the dependency of the soil moisture fluctuations on rainfall. There were smaller fluctuations in winter as a result of lower rainfall than in summer, during which the fluctuations in soil moisture were greater, because of more rainfall events. The CRP estimates correlated better in the wetter periods (slope $=0.976$ ) when the soil moisture values were above $30 \%$, compared to the drier periods (slope $=0.691$ ). The CRP estimated soil moisture on average 3.45 VWC (\%) higher throughout the validation period, when compared to the in-situ data set. This result is ascribed to differences in the measurement depths between the CRP and the in-situ instruments. Overall, the CRP-derived soil moisture followed the general trend of the in-situ soil moisture variations.

A graph of in-situ ( $x$-axis) versus the CRP ( $y$-axis) soil moisture estimates revealed that the majority of the points were above the 1:1 line (dotted) (Figure 7). There were no extreme outliers. The positive $y$-intercept of 12.024 indicated an over-estimation by the CRP of the lower values (when the soil was drier). There was a good agreement between both data sets, shown by the high $R^{2}(0.845)$.

A graph of the residuals (differences between the in-situ and CRP data sets) against time was plotted (Figure 8). The $\triangle \mathrm{VWC}(\%)$ was the difference between the in-situ (independent) and CRP (dependent) data sets. This graph is plotted to illustrate how the difference in variables change over time. Most of the residuals are negative, which indicates that the CRP over-estimates soil moisture when compared to the in-situ data set. In the drier periods, the residuals range from -0.52 to -11.54 VWC (\%) (with an average of -6.25 VWC (\%)), which indicates that the CRP over-estimates soil moisture throughout these periods. In the wet periods, the residuals vary from 6.16 to $-7.08 \mathrm{VWC}(\%)$ (with an average of -0.90 VWC (\%)). The CRP performed better in the wetter periods, when compared to the in-situ measurements, as the average absolute residual value is less than that of the corresponding drier periods.

Table 1: Calibrations, dates, gravimetric soil moisture, bulk density, neutron counts and calculated $\mathrm{N}_{0}$ values

\begin{tabular}{|c|c|c|c|c|c|c|}
\hline Calibration (date) & Moisture status & $\begin{array}{l}\text { Gravimetric water } \\
\text { content }(g / g)\end{array}$ & Bulk density $\left(\mathrm{g} / \mathrm{cm}^{3}\right)$ & $\begin{array}{l}\text { Volumetric water } \\
\text { content }\left(\mathrm{cm}^{3} / \mathrm{cm}^{3}\right)\end{array}$ & $\begin{array}{l}\text { Neutron count } \\
\text { (count/h) }\end{array}$ & $\mathrm{N}_{0}$ \\
\hline $1(09 / 07 / 2014)$ & Dry & 0.490 & 0.593 & 0.291 & 1731.684 & 3250.573 \\
\hline $2(28 / 08 / 2014)$ & Dry & 0.438 & 0.593 & 0.259 & 1761.408 & 3242.507 \\
\hline $3(02 / 12 / 2014)$ & Wet & 0.647 & 0.593 & 0.384 & 1652.600 & 3255.973 \\
\hline $4(22 / 01 / 2015)$ & Wet & 0.741 & 0.593 & 0.439 & 1611.059 & 3248.243 \\
\hline
\end{tabular}




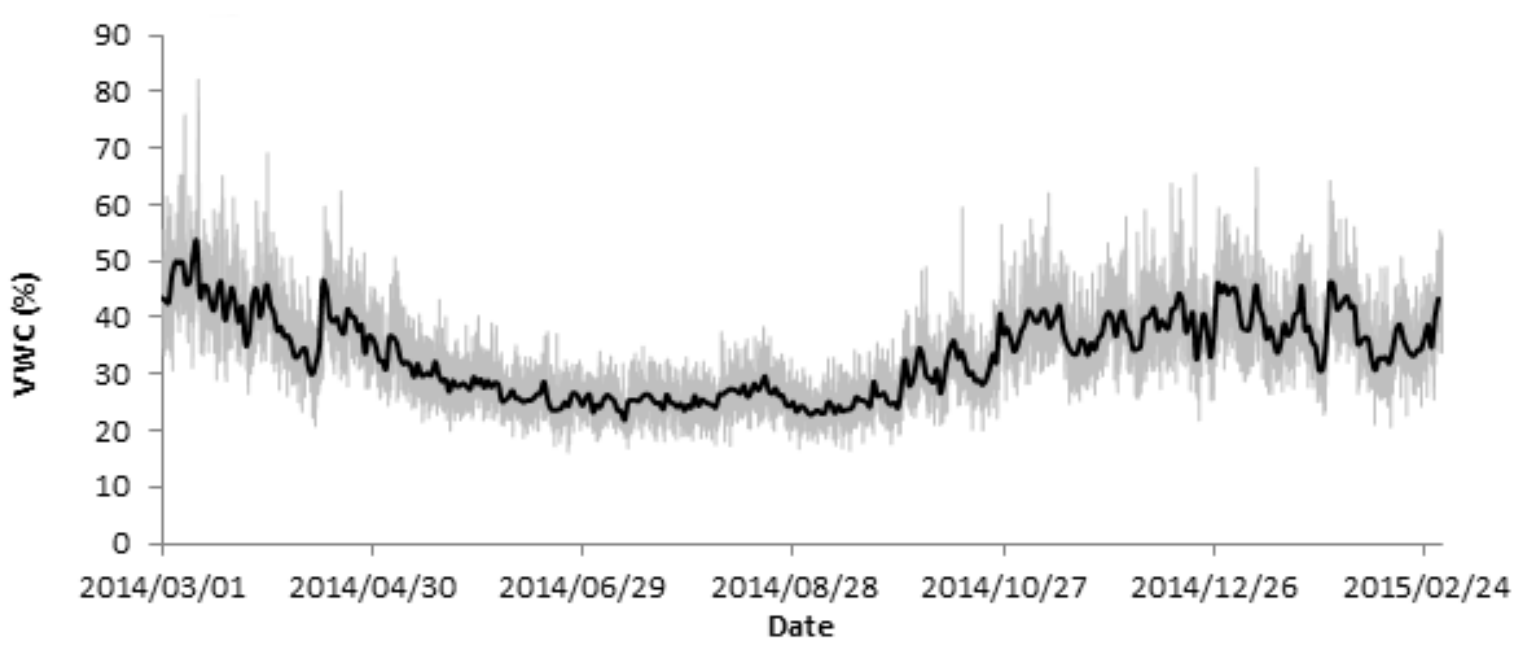

VWC, volumetric water content

Figure 4: Hourly (grey line) and daily (black line) soil moisture estimates using the calibrated cosmic ray probe.

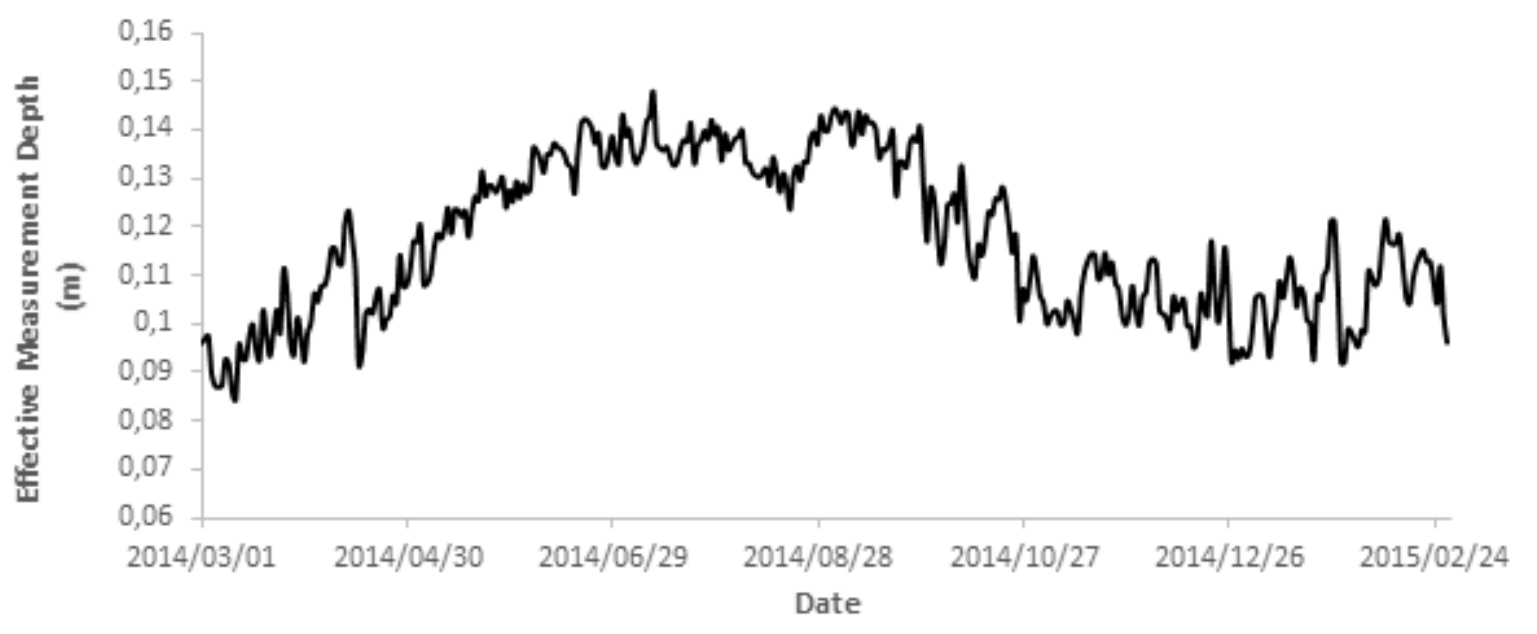

Figure 5: The cosmic ray probe's effective measurement depth $(\mathrm{m})$.

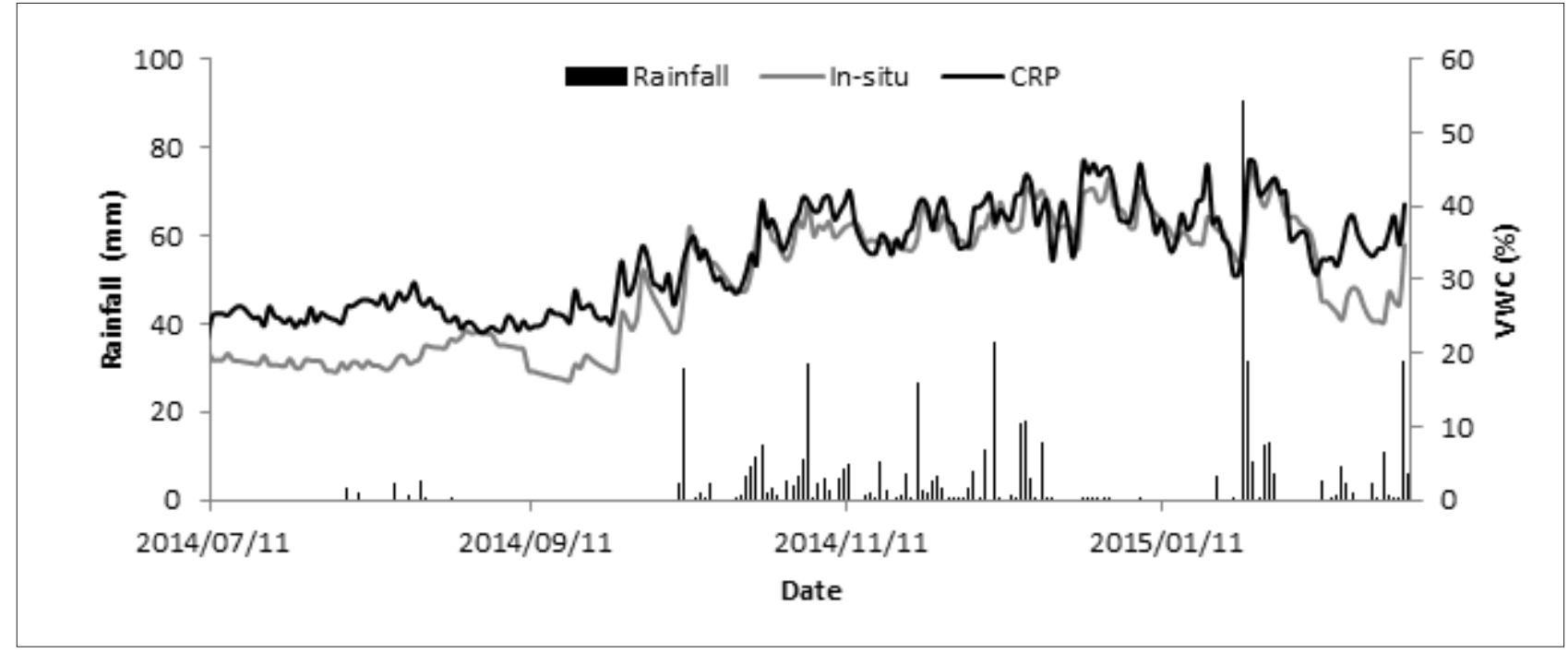

VWC, volumetric water content

Figure 6: Daily soil moisture estimates for Catchment VI using in-situ and cosmic ray probe (CRP) methods plotted against rainfall. 


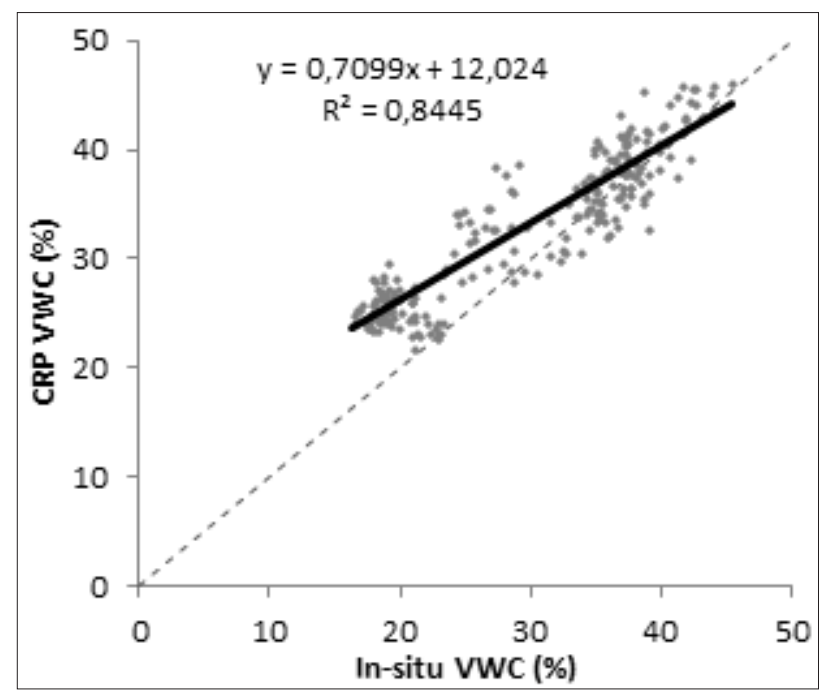

VWC, volumetric water content

Figure 7: Scatterplot of in-situ versus cosmic ray probe (CRP) soil moisture estimates for the period 11 July 2014 to 1 March 2015. The dotted line indicates the 1:1 line.

A paired $t$-test (Table 2) revealed that the mean of the CRP was 3.5\% higher than the in-situ data (negative $t$-statistic). The variance for the in-situ soil moisture was higher than the CRP by 30 and suggests the higher variation of point measurements when compared to the large area average of the CRP. The absolute value of the $t$-statistic (4.827) was greater than the critical two-tail value (1.965) and the $p$-value $\left(1.919 \times 10^{-6}\right)$ was less than the alpha value $(0.05)$ showing that there was a significant difference between the methods.

The differences between the in-situ and the CRP soil moisture estimates can be explained by the following. The in-situ data set was not the actual average of the catchment, but the average of the sensors in the catchment. If the sensors were placed in different locations in the catchment, the in-situ data set could be different.

The area covered by the in-situ sensors was smaller than that covered by the CRP. The in-situ soil moisture sensors were a maximum of $200 \mathrm{~m}$ away from the CRP; however, the CRP has a measurement footprint that exceeds $200 \mathrm{~m}$ in radius.
Table 2: $\quad$ Results of $t$-test comparing in-situ and cosmic ray probe (CRP) soil moisture estimates

\begin{tabular}{l|c|c}
\hline \hline & In-situ & CRP \\
\hline Mean & 29.557 & 33.005 \\
\hline Variance & 74.464 & 44.433 \\
\hline Number of observations & 233 & 233 \\
\hline Hypothesised mean difference & 0 & \\
\hline d.f. & 436 & \\
\hline$t$-statistic & -4.827 & \\
\hline$p(T<=t)$ two-tail & $1.919 \times 10^{-6}$ & \\
\hline$t$ :Critical two-tail & 1.965 & \\
\hline
\end{tabular}

The CRP was not measuring soil moisture at a constant depth throughout the validation period, as its measurement depth depends on the soil moisture content. When the soil was dry, the CRP probe was measuring at a deeper depth $(0.14 \mathrm{~m})$ than when the soil was wet $0.10 \mathrm{~m})$. The representative in-situ data set was measuring constantly at an average depth of $0.12 \mathrm{~m}$. Therefore, the dry periods did not correlate as well as the wet periods, as the measurement depths were different.

\section{Conclusions}

Understanding the spatial and temporal variability of soil moisture at different scales is of great importance in many land surface disciplines, such as hydrology. Soil moisture is a key hydrological variable, as it impacts the water and energy balance at the land surface-atmosphere interface and is the main water source for natural vegetation and agriculture. It is difficult to quantify and assess the soil moisture content at an intermediate scale, because of the heterogeneity in soil and landcover properties, climate drivers and topography.

The CRP, once properly calibrated, is suitable for providing spatial estimates of soil moisture, as the measurements correlated well with the representative in-situ soil moisture data set. The CRP calibration procedure described here is adequate for predicting soil moisture at a scale of around 18 ha; however, potential errors can be introduced throughout the procedure, which range from selecting the sample points

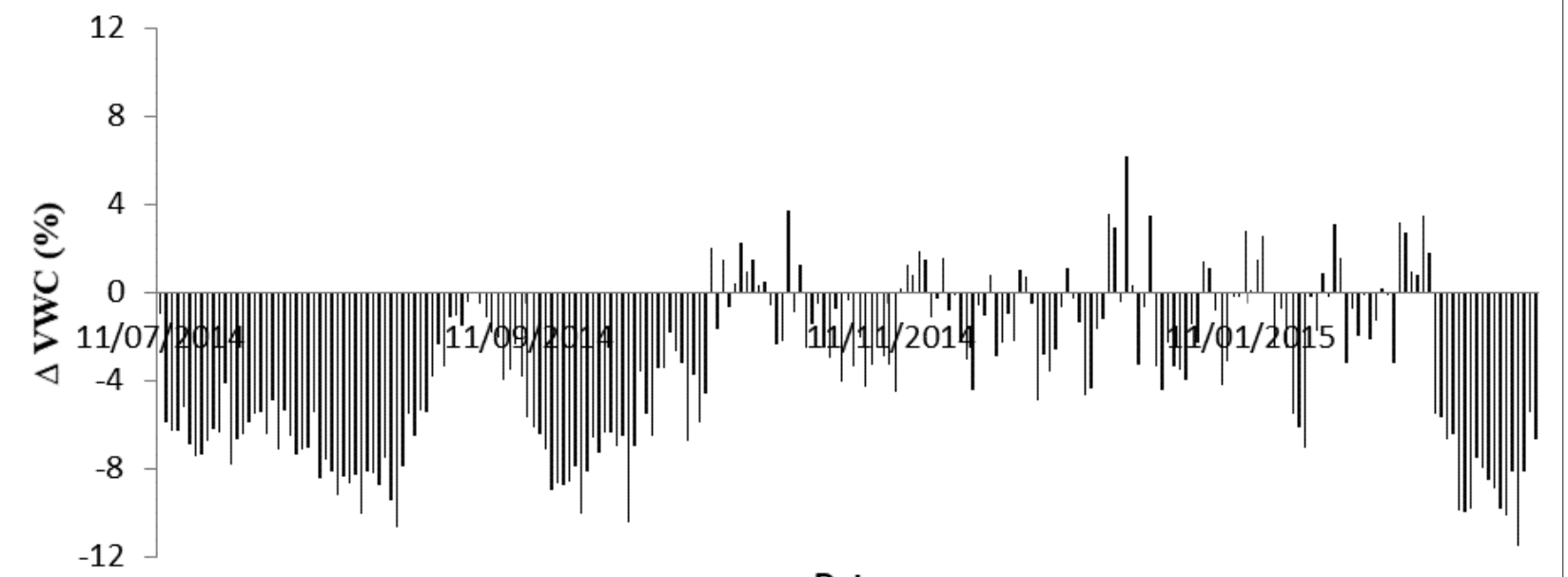

Date

VWC, volumetric water content

Figure 8: Residual graph of in-situ soil moisture estimates against those made using the cosmic ray probe. 
and determining a representative bulk density, to determining the average neutron count $\left(\mathrm{N}_{0}\right)$ value. Therefore, proper procedures must be adhered to in order to minimise potential errors. One calibration is sufficient for soils with sparse vegetation, but multiple calibrations obtained at different soil moisture contents provide a more accurate calibration. ${ }^{30}$

The validation of the CRP with a representative catchment soil moisture data set, from the in-situ soil moisture network, showed that the CRP is suitable for providing continuous spatial soil moisture estimates.

\section{Recommendations}

The following recommendations can be used to address the main limitations that were experienced in this research study. These recommendations will provide assistance for future research studies.

The calibration of the CRP is time and labour intensive, as numerous gravimetric soil samples within the measurement footprint at several depths are required. The use of a TDR Hydro-Sense probe, which obtains instantaneous measurements of volumetric soil moisture when inserted into the soil, can potentially be used to obtain the necessary soil moisture measurements for the calibration. Thus, it would greatly reduce the time and labour required, as well as eliminate the need to determine the bulk density which is needed to convert gravimetric soil moisture to volumetric soil moisture.

The validation of the CRP should ideally be done with in-situ soil moisture sensors at a variety of depths. Ideally, several TDR pits in the CRP measurement volume could be used. This approach would improve the validation, as the CRP does not measure at a constant depth. However, this approach would be very capital, time and labour intensive, as a dense network of TDR pits would be required.

The number of calibrations carried out against the accuracy of the calibrated CRP estimates needs to be considered. In theory, more calibrations carried out would result in more reliable estimates of soil moisture. In practice, each calibration requires time, labour and capital to conduct. Therefore, although we conducted four calibrations, reliable estimates could have been obtained with two calibrations, one each in opposing seasons.

\section{Authors' contributions}

T.V.: Setting up and calibrating the cosmic ray probe, writing the manuscript, editing the manuscript. C.E.: Supervision, setting up the cosmic ray probe, planning the logistics of the fieldwork, editing the manuscript. M.M.: Supervision, setting up the cosmic ray probe, calibrating procedures, editing the manuscript. T.F.: Cosmic ray probe teaching, calibration training, editing the manuscript.

\section{References}

1. Fang B, Lakshmi V. Soil moisture at watershed scale: Remote sensing techniques J Hydrol. 2014;516:258-272. http://dx.doi.org/10.1016/j. jhydrol.2013.12.008

2. Jackson TJ, Cosh MH, Bindlish R, Starks PJ, Bosch DD, Seyfried M, et al. Validation of advanced microwave scanning radiometer soil moisture products. IEEE Trans Geosci Remote Sens. 2010;48(12):4256-4272. http:// dx.doi.org/10.1109/TGRS.2010.2051035

3. Albergel C, De Rosnay P, Gruhier C, Mu noz-Sabater J, Hasenauer S, Isaksen $L$, et al. Evaluation of remotely sensed and modelled soil moisture products using global ground-based in situ observations. Remote Sens Environ. 2012;118:215-226. http://dx.doi.org/10.1175/JHM-D-11-0107.1

4. Mecklenburg S, Drusch M, Kerr Y, Font J, Roger O. ESA's soil moisture and ocean salinity mission: Mission performance and operations. IEEE Trans Geosci Remote Sens. 2012;50(5):1354-1366. http://dx.doi.org/10.1109/ TGRS.2012.2187666

5. Ni-Meister W. Soil moisture initialization for climate prediction: Characterization of model and observation errors. J Geophys Res. 2005;110:11-29. http:// dx.doi.org/10.1029/2004JD005745
6. Gruber A, Dorigo WA, Zwieback S, Xaver A, Wagner W. Characterizing coarse-scale representativeness of in situ soil moisture measurements from the International Soil Moisture Network. Vadose Zone J. 2013;12(2), Art. \#170, 16 pages. http://dx.doi.org/10.2136/vzj2012.0170

7. Kohli M, Shron M, Zreda M, Schmidt U, Dietrich P, Zacharias S. Footprint characteristics revised for field-scale soil moisture monitoring with cosmicray neutrons. Water Resour Res. 2015;10:5772-5790. http://dx.doi. org/10.1002/2015WR017169

8. Franz T, Zreda M, Ferre T, Rosolem R. An assessment of the effect of horizontal soil moisture heterogeneity on the area-average measurement of cosmic-ray neutrons. Water Resour Res. 2013;49:6450-6458. http://dx.doi. org/10.1002/wrcr.20530

9. Zreda M, Shuttleworth WJ, Zeng X, Zweck C, Desilets D, Franz T, et al. COSMOS: The COsmic-ray Soil Moisture Observing System. Hydrol Earth Syst Sci. 2012;16:4079-4099. http://dx.doi.org/10.5194/hess-16-40792012

10. Desilets D, Zreda M, Ferre T. Nature's neutron probe: Land surface hydrology at an elusive scale with cosmic rays. Water Resour Res. 2010;46, W11505, 7 pages. http://dx.doi.org/10.1029/2009WR008726

11. Kim S, Liu YY, Johnson FM, Parinussa RM, Sharma A. A global comparison of alternate AMSR2 soil moisture products: Why do they differ? Remote Sens Environ. 2015;161:43-62. http://dx.doi.org/10.1016/j.rse.2015.02.002

12. Walker JP, Willgoose GR, Kalma JD. In situ measurement of soil moisture: A comparison of techniques. J Hydrol. 2004;2963:85-99. http://dx.doi. org/10.1016/j.jhydrol.2004.01.008

13. Qin J, Yang K, Chen Y, Zhao L, Han M. Spatial up-scaling of in-situ soil moisture measurements based on MODIS-derived apparent thermal inertia. Remote Sens Environ. 2013;138:1-9. http://dx.doi.org/10.1016/j.rse

14. Ochsner TE, Cosh MH, Cuenca RH, Dorigo WA, Draper CS, Hagimoto Y, et al. State of the art in large-scale soil moisture monitoring. Soil Sci Soc Am J. 2013;77(6):1888-1919. http://dx.doi.org/10.2136/sssaj2013.03.0093

15. Jiao $Q$, Zhu Z, Du F. Theory and application of measuring mesoscale soil moisture by cosmic-ray fast neutron probe. 2014 IOP Conf Ser Earth Environ Sci. 2014;17, Art. \#012147, 8 pages. http://dx.doi.org/10.1088/1755$1315 / 17 / 1 / 012147$

16. Zreda M, Desilets D, Ferre TPA, Scott RL. Measuring soil moisture content non-invasively at intermediate spatial scale using cosmic-ray neutrons. Geophys Res Lett. 2008;35(21), L21402, 5 pages. http://dx.doi. org/10.1029/2008GL035655

17. Desilets D, Zreda M. Footprint diameter for a cosmic-ray soil moisture probe: Theory and Monte Carlo simulations. Water Resour Res. 2013;49:35663575. http://dx.doi.org/10.1002/wrcr.20187

18. Dutta R, D'este C. Virtual calibration of cosmic ray sensor: Using supervised ensemble machine learning. Int J Adv Comput Sci Applic. 2013;4(8):104110. http://dx.doi.org/10.14569/IJACSA.2013.040815

19. Franz T, Zreda M, Rosolem R, Ferre T. A universal calibration function for determination of soil moisture with cosmic-ray neutrons. Hydrol Earth Syst Sci. 2013;17:453-460. http://dx.doi.org/10.5194/hess-17-453-2013

20. Franz T, Zreda M, Rosolem R, Ferre T. Field validation of a cosmic-ray neutron sensor using a distributed sensor network. Vadose Zone J. 2012;11(4), Art. \#0046, 10 pages. http://dx.doi.org/10.2136/vzj2012.0046

21. Franz T, Wang T, Avery W, Finkenbiner C, Brocca L. Spatiotemporal characterization of soil moisture fields in agricultural areas using cosmic-ray neutron probes and data fusion. EGU General Assembly 2015; 2015 April 12-17; Vienna, Austria.

22. Gush M, Scott DF, Jewitt GPW, Schulze RE, Lumsden T, Hallowes L, et al. Estimation of streamflow reduction resulting from commercial afforestation in South Africa. WRC report TT 173/02. Pretoria: Water Research Commission; 2002.

23. Everson CS, Molefe GL, Everson TM. Monitoring and modelling components of the water balance in a grassland catchment in the summer rainfall area of South Africa. WRC report no: 493/1/98. Pretoria: Water Research Commission; 1998 
24. Kuenene BT, Van Huyssteen CW, Hensley M. Soil water saturation in the Cathedral Peak VI catchment, KwaZulu-Natal. Paper presented at: SAGA Biennial Technical Meeting and Exhibition; 2009 September 16-18; Swaziland. p. 565-570. Available from: http://www.earthdoc.org/publication/ publicationdetails/?publication $=51554$

25. Mucina L, Rutherford MC. The vegetation of South Africa, Lesotho and Swaziland. Pretoria: South African National Biodiversity Institute; 2006.

26. Scott DF, Prinsloo FW, Moses G, Mehlomakulu M, Simmers ADA. A reanalysis of the South African catchment afforestation experimental data. WRC report no. 810/1/00.Pretoria: Water Research Commission; 2000.
27. Jarmain C, Govender M, Everson CS. Improving the basis for predicting total evaporation from natural veld types in South Africa. WRC report no. 1219/1/04. Pretoria: Water Research Commission; 2004.

28. Franz T. Stationary probe data calculations. Lincoln, NE: Franz Hydrogeophysics Lab Group, University of Lincoln-Nebraska; 2014. p. 1-4.

29. Everson CS, Everson TM. The long-term effects of fire regime on primary production of montane grasslands in South Africa. Afr J Range For Sci. 2016;33(1):33-41. http://dx.doi.org/10.2989/10220119.2015.1124922

30. Zreda M. Land-surface hydrology with cosmic-ray neutrons: Principles and applications. J Jpn Soc Soil Phys. 2016;132:25-30. 